\title{
IMOBILISASI POLUTAN Fe DAN Pb DALAM LIMBAH OLI BEKAS DENGAN SOLIDIFIKASI/STABILISASI
}

\section{The Fe And Pb Polutant Imobilization in Lubricant Waste By Solidification/Stabilization Process}

\author{
Monik Kasman ${ }^{1 \star}$, Suhendra ${ }^{1}$, Peppy Herawati ${ }^{1}$, Salmariza Sy ${ }^{2}$, Hariyanto ${ }^{1}$, Fitri Yanti ${ }^{1}$ \\ ${ }^{1}$ Program Studi Teknik Lingkungan, Fakultas Teknik, Universitas Batanghari \\ Jl. Slamet Riyadi, Broni, Jambi. \\ ${ }^{2}$ Balai Riset dan Standardisasi Industri Padang, JI. Raya LIK No. 23 Ulu Gadut Padang. \\ * e-mail: emka_engineer@yahoo.com
}

\section{Diterima: 18 Agustus 2016, revisi akhir: 9 Desember 2016 dan disetujui untuk diterbitkan: 14 Desember 2016}

\begin{abstract}
ABSTRAK
Limbah oli bekas dikategorikan sebagai limbah B3 dalam PP 101 tahun 2014 yang berpotensi membahayakan makhluk hidup dan lingkungan. Solidifikasi/stabilisasi merupakan salah satu cara untuk mengatasi permasalahan limbah B3. Upaya ini dilakukan dengan proses solidifikasi/stabilisasi (s/s) limbah oli bekas dengan campuran semen dan pasir silika menjadi bentuk mortar berukuran $(5 \times 5 \times 5) \mathrm{cm}$. Penelitian bertujuan untuk mengidentifikasi pengaruh rasio oli bekas terhadap air (o/a) dan umur mortar terhadap efektivitas proses s/s tersebut melalui uji kualitas mortar secara fisik dan kimia. Uji tersebut meliputi uji kuat tekan dan uji perlindian (toxicity characteristic leaching procedure). Hasil penelitian menunjukkan bahwa nilai kuat tekan untuk rasio o/a 0\%:100\%, 15\%:85\% dan 25\%:75\% pada umur mortar 7 hari, 14 hari dan 28 hari memenuhi nilai kuat tekan yang ditetapkan oleh SNI-15-7064 2004 dan ASTM C150-02. Uji perlindian sampel mortar untuk rasio o/a 0\%:100\%, 15\%:85\% dan 25\%:75\% pada umur mortar 7 hari, 14 hari, dan 28 hari menunjukkan bahwa konsentrasi $\mathrm{Pb}$ adalah berkisar $0,517 \times 10^{-6}-0,612 \times 10^{-6} \mathrm{mg} / \mathrm{L}$, dan konsentrasi Fe berkisar $0,174 \times 10^{-6}-0,780 \times 10^{-6} \mathrm{mg} / \mathrm{L}$. Konsentrasi Pb kurang dari konsentrasi baku mutu atau dapat dikatakan lolos uji TCLP lampiran PP 101 tahun 2014.
\end{abstract}

Kata kunci: limbah oli bekas, solidifikasi/stabilisasi, rasio o/a, kuat tekan, TCLP

\begin{abstract}
Lubricant waste is categorized as hazardous waste stated in government regulation (PP) 101/2014. It could dangers human being and environment. This problem can be addressed by solidification/stabilization process. In this work, lubricant waste was solidified/stabilized in a mixture of lubricant waste with cement as binder and silica sand into mortar sized of $(5 \times 5 \times 5) \mathrm{cm}$. This study was aimed to investigate the influences of ratio of lubricant waste to water (ratio o/a) and curing time or age of mortar to the effectiveness of $\mathrm{s} / \mathrm{s}$ process by testing mortar quality physically and chemically. The test includes compressive strenght test and leaching test (toxicity characteristic leaching procedure). The results showed compressive strenght value for mortar with the ratio o/a 0\%:100\%, 15\%:85\%, and $25 \%: 75 \%$ in the age of mortar 7 days, 14 days, and 28 days was met the compressive strenght value qualification standardized by SNI-15-7064.2004 and ASTM C150-02. The test of samples mortar leached using TCLP test method showed that the concentration of $\mathrm{Pb}$ and Fe for the ratio o/a 0\%:100\%, 15\%:85\%, dan 25\%:75\% and age of mortar 7 days, 14 days, and 28 days ranges $0,517 \times 10^{-6}-0,612 \times 10^{-6} \mathrm{mg} / \mathrm{L}$, and $0,174 \times 10^{-6}-0,780 \times 10^{-6} \mathrm{mg} / \mathrm{L}$ respectively. The concentrations of $\mathrm{Pb}$ were less than the concentration of quality standard and pass the TCLP test defined by attachment of government regulation (PP) 101/2014.
\end{abstract}

Keywords: lubricant waste, solidification/stabilization, ratio o/a, compressive strenght, TCLP 


\section{PENDAHULUAN}

Limbah atau residu oli bekas mengandung sisa hasil pembakaran yang bersifat asam, korosif, deposit, dan mengandung logam berat yang bersifat karsinogenik meliputi kontaminan utama organik dan anorganik (Zain et al., 2014 (1)). Pesatnya perkembangan industri dan jumlah kendaraan bermotor memicu peningkatan kuantitas limbah oli bekas. PT. Wiraswasta Gemilang Indonesia (WGI) sebagai produsen oli bekas terbesar di Indonesia memproduksi oli 75 juta liter pertahun. Satu liter oli bekas diperkirakan dapat merusak jutaan liter air segar dari sumber air dalam tanah (Fitriawan, 2010). Limbah oli bekas yang tidak dikelola dengan baik merupakan sumber potensial kontaminan seperti besi dan timbal yang membahayakan makhluk hidup dan lingkungan.

Berdasarkan Peraturan Pemerintah Nomor 101 tahun 2014, limbah oli bekas diklasifikasikan sebagai limbah B3 sehingga penanganannya pun harus memenuhi kaidah-kaidah dalam peraturan tersebut. Penanganan yang direkomendasikan adalah solidifikasi/ stabilisasi dimana dengan proses tersebut sifat B3 dalam oli bekas akan menjadi stabil dan dapat dimanfaatkan sebagai produk yang aman bagi kesehatan dan lingkungan. Selama ini, metode pemanfaatan oli bekas hanya sebatas untuk menjadi bahan baku bahan bakar cair (Wijaya dan Rahardjo, 2011), bahan bakar mesin diesel, campuran minyak tanah dan bahan peremaja pada daur ulang jalan aspal (Ismanto, 2010). Metode lainya adalah pemanfaatan oli bekas sebagai bahan bakar campuran hidrokarbon (Fitriawan, 2010).

Stabilisasi adalah suatu teknik mereduksi pencemar berbahaya dalam limbah dengan mengubah kontaminan seperti memperkecil daya larut, pergerakan dan racunnya. Solidifikasi adalah teknik mengkapsulasi limbah ke bentuk padat tanpa memerlukan intereaksi secara kimia antara kontaminan dan zat pemadat aditif. Kedua proses ini sering digabung dan terjadi bersamaan, kombinasi proses solidifikasi dan stabilisasi dikenal dengan istilah "fiksasi limbah" atau "enkapsulasi" atau disingkat dengan s/s (Spence \& Shi, 2005; Voglar \& Lestan, 2011; Wang et al., 2012). Prinsip kerja stabilisasi/solidifikasi adalah pengubahan watak fisik dan kimiawi limbah B3 dengan cara penambahan senyawa pengikat (landfill) sehingga pergerakan senyawasenyawa B3 dapat dihambat atau terbatasi dan membentuk ikatan massa monolit dengan struktur yang kekar (massive). Hasil dari solidifikasi/stabilisasi dapat dibuang ke landfill atau dimanfaatkan sebagai bahan konstruksi (Spence \& Shi, 2005). Dari hasil penelitian Zain et al., (2014 (1), (2)), solidifikasi/stabilisasi dapat mereduksi kontaminan organik dan anorganik dalam lumpur minyak bumi. Kualitas mutu mortar yang dihasilkan ditinjau dari kuat tekan juga memenuhi kriteria kuat tekan mengacu pada standar kuat tekan ASTM C150-02.

Penelitian ini bertujuan untuk menguji metode solidifikasi/stabilisasi dalam pemanfaatan limbah oli bekas sebagai bahan campuran pembuatan mortar yang kuat dan aman bagi lingkungan. Pengujian dilakukan dengan mengamati karakteristik mekanik yaitu kuat tekan dan karakteristik kimia yaitu tingkat perlindian mortar. Tingkat perlindian mortar (leaching) dilakukan dengan uji TCLP (Toxicity Characteristic Leaching Procedure) untuk menentukan konsentrasi logam besi (Fe) dan timbal $(\mathrm{Pb})$.

\section{METODOLOGI PENELITIAN}

Penelitian bersifat eksperimental kuantitatif. Solidifikasi/stabilisasi dilakukan terhadap limbah oli bekas dengan campuran semen dan pasir hingga menjadi bentuk mortar.

\section{Persiapan Bahan}

Bahan yang digunakan adalah semen sebagai pengikat (binder), pasir silika, dan air suling. Peralatan yang digunakan meliputi ayakan, meja leleh Compressive mortar, mixer, oven, cetakan mortar berbentuk kubus dengan ukuran $(5 \times 5 \times 5) \mathrm{cm}$, mesin uji kuat tekan untuk menentukan kuat tekan mortar dengan kapasitas 1000 KN, gelas-gelas kimia, 
desikator, penumbuk dan spatula, dan jangka sorong.

\section{Pembuatan Mortar}

1) Bahan dicampur dengan menggunakan mixer dan kemudian lakukan percobaan leleh mortar dengan cara mengisikan campuran mortar ke dalam cetakan leleh yang terletak di atas meja leleh.

2) Setelah tercampur dengan sempurna (homogen) kemudian dilakukan pencetakan. Masing-masing sampel dibuat triplikasi.

3) Perawatan (curing time), selanjutnya dibiarkan selama 1×24 jam kemudian cetakan mortar tersebut dibuka. dan dilanjutkan perendaman sesuai dengan umur yang diinginkan. Setelah masa curing time dianggap sudah mencukupi, mortar tersebut disimpan pada tempat yang terlidung dari sinar matahari agar penguapan dapat terjadi secara perlahan-lahan.
4) Pengujian ini dilakukan terhadap kuat tekan mortar. Kemudian, dilakukan uji toksisitas mortar (uji TCLP). Pengujian kuat tekan mengacu pada SNI-036825.2002 dan SNI-15-7064-2004 (mutu kuat tekan) dan uji TCLP mengacu pada US EPA dan lolos uji TCLP (Lampiran PP 101 Tahun 2014).

\section{Variabel Penelitian}

Eksperimen dilakukan dengan memvariasikan umur mortar dan rasio oli bekas terhadap air (o/a). Efektivitas solidifikasi/stabilisasi ditentukan berdasarkan kualitas mortar. Pembahasan kualitas mortar hasil solidifikasi/stabilisasi oli bekas dibatasi pada kuat tekan dan konsentrasi $\mathrm{Pb}$ dan $\mathrm{Fe}$ hasil uji TCLP. Umur mortar pada penelitian ini adalah 7 hari, 14 hari, dan 28 hari. Rasio oli bekas terhadap air dan komposisi mortar dapat dilihat pada Tabel 1.

Tabel 1. Komposisi mortar

\begin{tabular}{ccccccc}
\hline Sampel & $\begin{array}{c}\text { Pasir } \\
\text { gr }\end{array}$ & $\begin{array}{c}\text { Semen } \\
\text { gr }\end{array}$ & $\begin{array}{c}\text { Oli bekas } \\
\%\end{array}$ & $\begin{array}{c}\text { Air } \\
\%\end{array}$ & $\begin{array}{c}\text { Oli bekas } \\
\text { gr }\end{array}$ & $\begin{array}{c}\text { Air } \\
\text { gr }\end{array}$ \\
\hline 1 & 1017,5 & 370 & $15 \%$ & $85 \%$ & 27 & 153 \\
2 & 1017,5 & 370 & $25 \%$ & $75 \%$ & 45 & 135 \\
3 & 1017,5 & 370 & 0 & $100 \%$ & 0 & 180 \\
\hline
\end{tabular}

\section{Pengujian}

Kuat tekan mortar diuji dengan mesin uji kuat tekan kapasitas $1000 \mathrm{KN}$. Sampel mortar setelah memenuhi umurnya dikeringkan dalam suhu ruang selama 24 jam. Kemudian, sampel mortar diletakkan pada mesin kuat tekan, dan ditekan secara perlahan hingga benda uji runtuh dan hancur. Bacaan skala pada jarum penunjuk dicatat sebagai beban maksimum. Secara matematika rumus kuat tekan:

$$
f^{\prime} m=\frac{P}{A}
$$

$f^{\prime} m=$ kuat tekan mortar, dalam MPa

$P=$ beban maksimum total, dalam $\mathrm{N}$

$A=$ luas bidang tekan, dalam $\mathrm{mm}^{2}$

Uji perlindian logam mengacu kepada uji TCLP dilakukan pada sample mortar dengan mengekstrak $50 \mathrm{gr}$ sampel terlebih dahulu. Proses ekstraksi dibantu dengan penambahan pelarut asam asetat $(\mathrm{pH} 5)$. Perbandingan berat limbah padat B3 dengan pelarut asam asetat yaitu 1:20. Kemudian larutan diaduk dengan rotary agitator berkecepatan $30 \pm 2 \mathrm{rpm}$ selama $18 \pm 2$ jam. Terakhir, larutan disaring dengan kertas saring whatman GF/F pori 0,7 . Filtrat larutan tersebut dibaca dengan spektrofotometer serapan atom nyala (AAS). 


\section{HASIL DAN PEMBAHASAN}

Spence \& Shi (2005) menyatakan bahwa faktor yang mempengaruhi solidifikasi/stabilisasi limbah B3 adalah faktor air semen (FAS) yaitu angka perbandingan antara berat air dan berat semen dalam campuran mortar; jumlah semen; umur mortar; dan sifat agregat. Dalam hal ini, umur mortar dan rasio oli terhadap air merupakan dua faktor yang mempengaruhi proses solidifikasi/ stabilisasi limbah oli bekas dalam bentuk mortar. Secara fisik, mortar hasil solidifikasi/stabilisasi (s/s) dapat dilihat pada Gambar 1.

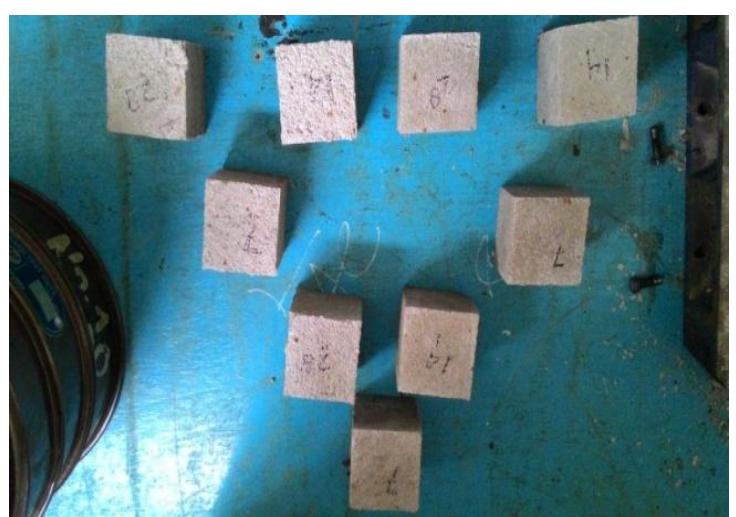

Gambar 1. Mortar hasil s/s limbah oli bekas

\section{Uji Parameter Fisik}

Sifat agregat yang berpengaruh terhadap kekuatan ialah bentuk, kekasaran permukaan, kekerasan, dan ukuran maksimum butir agregat. Bentuk dari agregat akan berpengaruh sebagai pengikat antar agregat. Kuat tekan menggambarkan mutu mortar. Semakin tinggi nilai kuat tekan mortar akan semakin tinggi pula mutu mortar. Hasil pengujian kuat tekan pada mortar dapat dilihat pada Tabel 2 dan Gambar 2.

Dari Tabel 2 terlihat bahwa nilai kuat tekan mortar pada semua variasi o/a lebih rendah daripada nilai kuat tekan mortar blangko (o/a bernilai 0\%:100\%). Hasil eksperimen menunjukkan rasio campuran oli bekas terhadap air dan umur mortar mempengaruhi nilai kuat tekan. Mortar dengan rasio o/a 25\%:75\% mempunyai nilai kuat tekan yang lebih tinggi daripada mortar dengan rasio o/a 15\%:85\%.

Secara keseluruhan nilai kuat tekan rasio o/a 15\%:85\% dan 25\%:75\% masih memenuhi kriteria nilai kuat tekan dalam SNI-15-7064.2004 dan ASTM C150-02. Lebih jelasnya, komparasi hasil eksperimen dengan SNI-15-7064.2004 dan ASTM C150-02 untuk umur mortar 7, 14, dan 28 hari dapat dilihat pada Tabel 3.

Kuat tekan rata-rata mortar umur 7 hari hari adalah $201 \mathrm{~kg} / \mathrm{cm}^{2}$, umur 14 hari adalah $296 \mathrm{~kg} / \mathrm{cm}^{2}$, dan umur 28 hari adalah 351 $\mathrm{kg} / \mathrm{cm}^{2}$. Semakin lama umur mortar maka kuat tekan akan semakin meningkat pula.

Tabel 2. Pengujian kuat tekan mortar

\begin{tabular}{lccc}
\hline Rasio o/a & \multicolumn{3}{c}{ Kuat Tekan* $\left(\mathrm{kg} / \mathrm{cm}^{2}\right)$} \\
\cline { 2 - 4 } & 7 hari & 14 hari & 28 hari \\
\hline 0\%:100\% (Blanko) & 281,136 & 337,526 & 369,137 \\
$15 \%: 85 \%$ & 153,970 & 249,831 & 312,033 \\
$25 \%: 75 \%$ & 205,983 & 301,836 & 357,92 \\
\hline
\end{tabular}

${ }^{*}$ Hasil rata-rata

Tabel 3. Komparasi kuat tekan hasil eksperimen dengan SNI-15-7064.2004 dan ASTM C150-02

\begin{tabular}{cccc}
\hline \multirow{2}{*}{ Umur mortar } & \multicolumn{3}{c}{ Standar Kuat Tekan $\left(\mathrm{kg} / \mathrm{cm}^{2}\right)$} \\
\cline { 2 - 4 } & Hasil & SNI-15-7064.2004 & ASTM C150-02 \\
\hline 7 hari & 201 & $\geq 125$ & $\geq 122$ \\
14 hari & 296 & $\geq 200$ & $\geq 194$ \\
28 hari & 351 & $\geq 250$ & $\geq 298$ \\
\hline
\end{tabular}




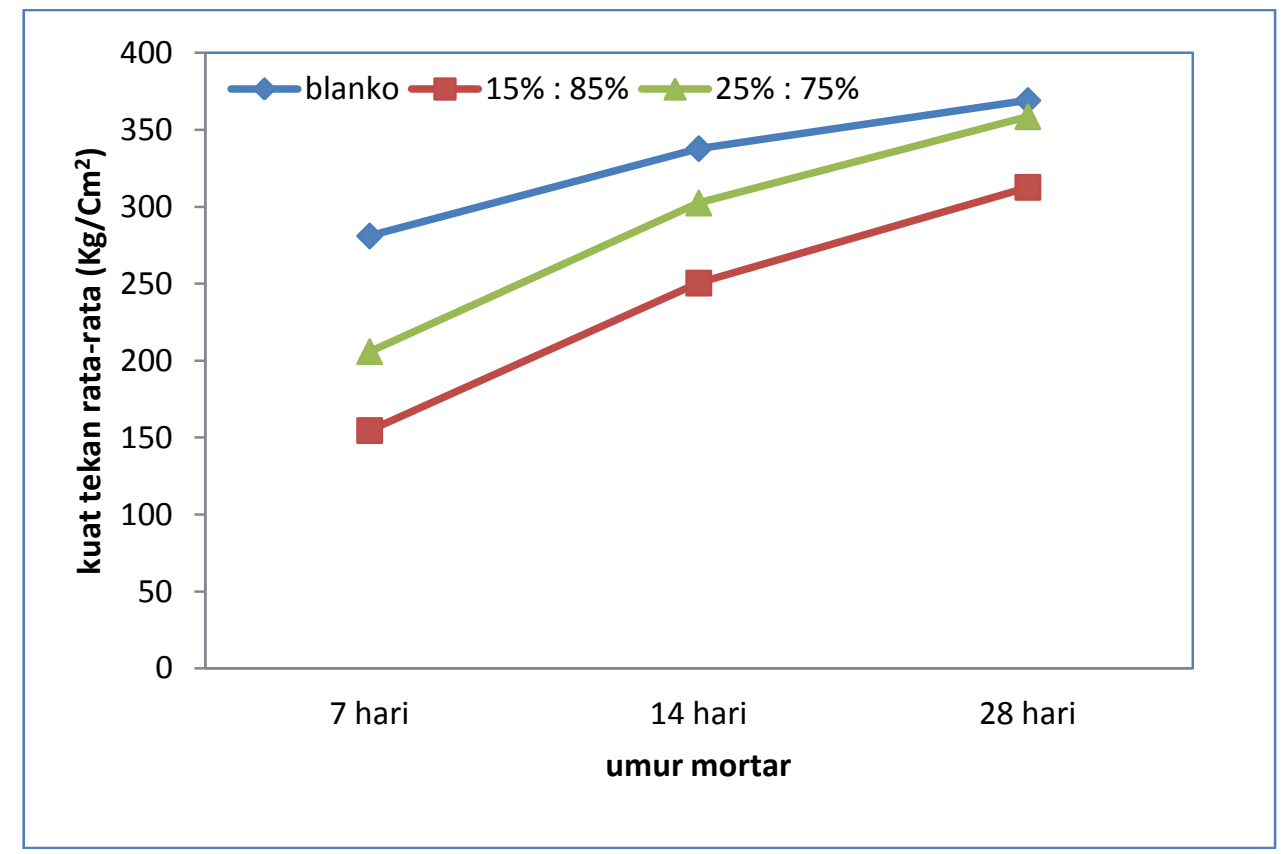

Gambar 2. Hasil pengujian kuat tekan mortar

\section{Uji Perlindian Mortar (TCLP test)}

Uji Toxicity Characteristic Leaching Procedure merupakan salah satu metode pengujian untuk mengetahui tingkat pelepasan logam berat pada mortar yang terbuat dari limbah oli bekas. Seperti diketahui dalam limbah oli bekas mengandung logam berat yang berasal dari sisa-sisa emisi gas buangan dalam kendaraan bermotor, pada penelitian ini logam berat yang akan dianalisis adalah $\mathrm{Pb}$ dan Fe. Dari hasil uji TCLP diperoleh kandungan logam berat seperti yang ditampilkan pada Tabel 4, Tabel 5 dan Tabel 6.

\section{Konsentrasi Fe}

Tabel 3 memperlihatkan bahwa konsentrasi Fe hasil uji TCLP pada mortar sangat dipengaruhi oleh komposisi mortar. Semakin lama umur mortar semakin tinggi konsentrasi Fe.

Pertambahan umur mortar akan memperlama proses hidrasi atau terjadinya reaksi kimia antara semen dan air. Pada proses hidrasi terjadi pengerasan mortar, dimana makin lama umur mortar maka proses hidrasi semakin sempurna (Spence \& Shi, 2005). Pada proses hidrasi tersebut diduga kandungan logam dalam campuran air dan oli bereaksi dengan semen, sehingga mampu menyerap logam dalam oli bekas. Makin lama umur mortar atau umur perawatan mortar, semakin tinggi konsentrasi logam yang terserap. Singkatnya, pergerakan logam dapat dicegah atau logam seperti $\mathrm{Fe}$ terimobilisasi dalam mortar oli bekas.

Tabel 3. Konsentrasi Fe Hasil uji TCLP

\begin{tabular}{lc}
\hline \multicolumn{1}{c}{ Sampel } & $\begin{array}{c}\text { Hasil Uji } \\
\times 10^{-6}(\mathrm{mg} / \mathrm{L})\end{array}$ \\
\hline Blanko 7 hari & 0,177 \\
Blanko 14 hari & 0,196 \\
Blanko 28 hari & 0,335 \\
15\%: 85\% 7 hari & 0,263 \\
15\%: 85\% 14 hari & 0,551 \\
15\%: 85\% 28 hari & 0,612 \\
25\%: 75\% 7 hari & 0,174 \\
$25 \%: 75 \%$ 14 hari & 0,318 \\
25\%: 75\% 28 hari & 0,78 \\
\hline
\end{tabular}

Zain (2014) juga menyimpulkan hal yang sama bahwa kandungan logam dalam limbah minyak bumi dapat diimobilisasi dengan proses solidifikasi/stabilisasi. Gambar 3 memperlihatkan secara jelas perbandingan konsentrasi $\mathrm{Fe}$ untuk semua variasi komposisi. Konsentrasi $\mathrm{Fe}$ terendah terkandung pada mortar dengan rasio o/a 
25\%:75\% umur 7 hari yaitu $0,174 \times 10^{-6}$ $\mathrm{mg} / \mathrm{L}$. Mortar dengan rasio o/a 25\%:75\% hanya mengandung $25 \%$ oli bekas dalam berat cairan yang digunakan dalam pembuatan mortar oli bekas. Semakin rendah rasio oli bekas terhadap air, maka semakin sedikit kandungan oli bekas dalam mortar. Semakin sedikit kandungan oli bekas dalam mortar, maka akan memperkecil konsentrasi logam Fe dalam mortar.

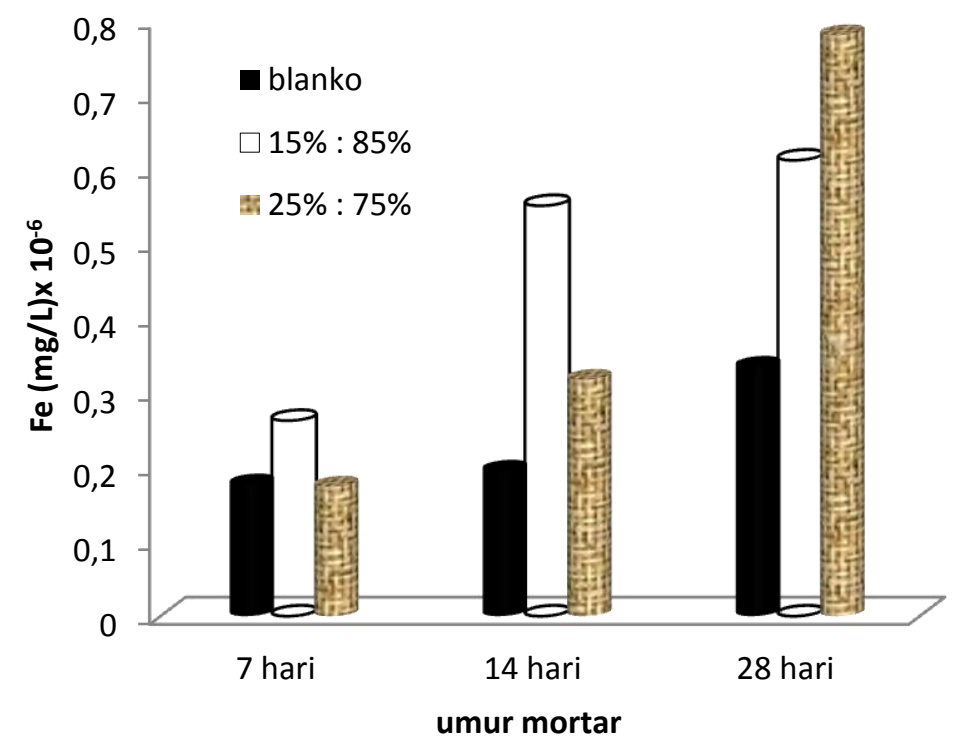

Gambar 3. Konsentrasi Fe Hasil uji TCLP

\section{Konsentrasi $\mathbf{P b}$}

Berdasarkan Tabel 4, konsentrasi $\mathrm{Pb}$ hasil uji TCLP mortar terlihat hampir sama. Proses solidifikasi/stabilisasi terjadi dengan baik dimana konsentrasi mortar untuk semua rasio benda di bawah baku mutu TCLP ( 0,5 ppm). Hal ini diperjelas pada Gambar 4.
Dari gambar 4 terlihat jelas bahwa hasil uji TCLP mortar yang berasal dari campuran pasir, semen, dan oli bekas pada semua komposisi sangat rendah dan berada di bawah ambang batas baku mutu TCLP berdasarkan pada PP No.101 Tahun 2014.

Tabel 4. Konsentrasi Pb hasil uji TCLP

\begin{tabular}{clcc}
\hline No & \multicolumn{1}{c}{ Sampel } & $\begin{array}{c}\text { Konsentrasi } \\
\times 10^{-6}(\mathrm{mg} / \mathrm{L})\end{array}$ & $\begin{array}{c}\text { Baku Mutu* } \\
(\mathrm{mg} / \mathrm{L})\end{array}$ \\
\hline 1 & Blanko 7 hari & 0,527 & 0,5 \\
2 & Blanko 14 hari & 0,523 & 0,5 \\
3 & Blanko 28 hari & 0,517 & 0,5 \\
4 & $15 \%: 85 \%$ 7 hari & 0,542 & 0,5 \\
5 & $15 \%: 85 \%$ 14 hari & 0,658 & 0,5 \\
6 & $15 \%: 85 \%$ 28 hari & 0,539 & 0,5 \\
7 & $25 \%: 75 \%$ 7 hari & 0,541 & 0,5 \\
8 & $25 \%: 75 \%$ 14 hari & 0,551 & 0,5 \\
9 & $25 \%: 75 \%$ 28 hari & 0,612 & 0,5 \\
\hline
\end{tabular}

*Lampiran PP 101 tahun 2014 


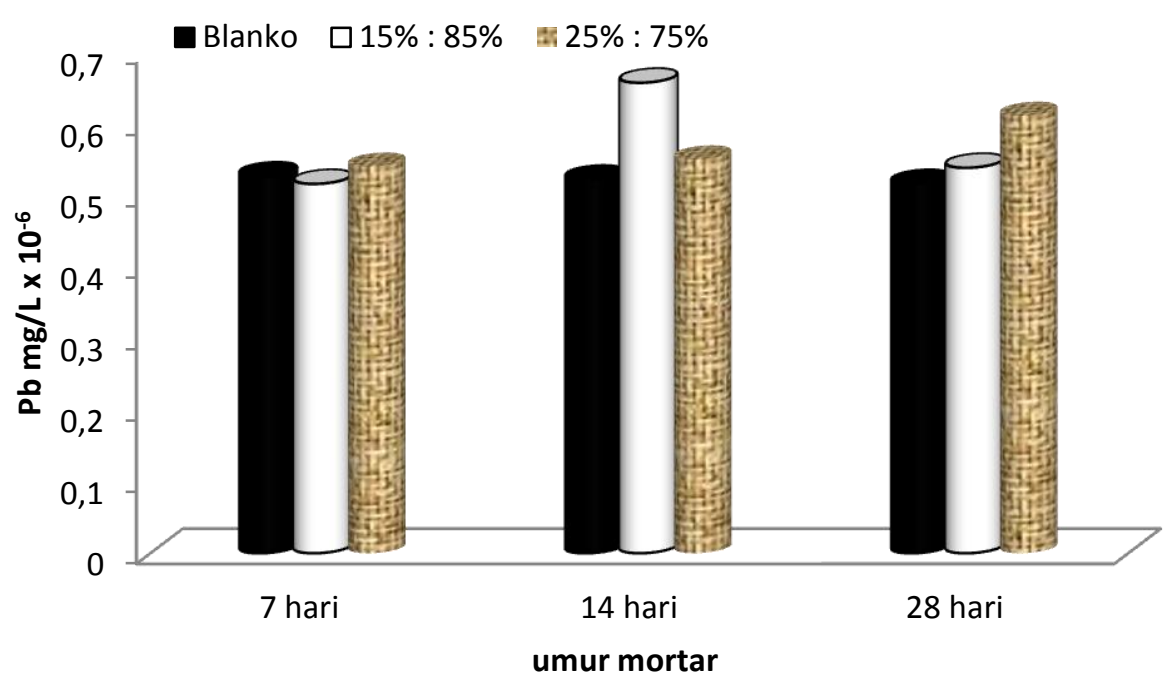

Gambar 4. Konsentrasi Pb hasi uji TCLP

Hasil penelitian menunjukkan bahwa solidifikasi/stabilisasi limbah oli bekas dalam bentuk mortar menghasilkan mortar dengan kualitas yang memenuhi standar secara fisika dan kimia. Kuat tekan sampel mortar untuk semua variasi komposisi dan semua umur mortar memenuhi kuat tekan yang ditetapkan oleh SNI-15-7064.2004 dan ASTM C150-02. Uji perlindian sampel mortar menunjukkan bahwa konsentrasi $\mathrm{Pb}$ sampel mortar untuk semua variasi komposisi dan umur mortar kurang dari konsentrasi baku mutu atau dapat dikatakan lolos uji TCLP lampiran PP 101 tahun 2014. Demikian halnya dengan konsentrasi $\mathrm{Fe}$, walaupun baku mutunya tidak tercantum dalam lampiran PP 101 tahun 2014, konsentrasi $\mathrm{Fe}$ yang dihasilkan sangat rendah. Bila dibandingkan dengan Permenkes 492 tahun 2010 tentang persyaratan kualitas air minum, maka konsentrasi Fe sampel mortar lebih rendah dari baku mutu yang ditetapkan.

Walaupun dalam penelitian ini limbah oli bekas yang digunakan hanya $25 \%$ dan $15 \%$ dari berat air campuran sampel mortar, hasil penelitian ini telah membuktikan bahwa solidifikasi/stabilisasi dapat menjadi salah satu solusi untuk memanfaatkan limbah oli bekas. Hal ini senada dengan pernyataan Zain et al., (2014 (1), (2)) yang memanfaatkan lumpur minyak bumi menjadi bentuk mortar dengan solidifikasi/stabilisasi.

\section{KESIMPULAN}

Solidifikasi/stabilisasi limbah oli bekas dalam bentuk mortar terbukti menghasilkan mortar dengan kuat tekan memenuhi SNI-15-7064.2004 dan ASTM C150-02 serta lolos uji TCLP lampiran PP 101 tahun 2014. Rasio limbah oli bekas terhadap air (o/a) dan umur mortar berpengaruh terhadap kuat tekan. Kuat tekan sampel mortar dengan rasio o/a 25\%:75\% lebih tinggi daripada rasio o/a 15\%:85\% dan makin lama umur mortar makin tinggi kuat tekan mortar. Dari uji TCLP, sampel mortar hasil proses solidifikasi/stabilisasi limbah oli bekas konsentrasi $\mathrm{Fe}$ dan $\mathrm{Pb}$ pada rasio o/a blanko, rasio o/a 25\%:75\%, dan rasio o/a 15\%:85\% sangat rendah. Konsentrasi $\mathrm{Pb}$ kurang dari ambang batas baku mutu TCLP menurut PP 101/2014.

\section{UCAPAN TERIMA KASIH}

Penulis menyampaikan terima kasih pada KEMENRISTEKDIKTI untuk dukungan finansial dalam riset ini melalui skim DIPA HIBAH BERSAING KEMENRISTEKDIKTI 2016. Terima kasih juga penulis sampaikan untuk semua staf di Laboratorium Teknik Universitas Batanghari dan mahasiswa yang telah membantu terlaksananya riset ini. 


\section{DAFTAR PUSTAKA}

ASTM. ASTM Standards C 150-02 Standard Specification for Portland Cement. USA

BSN. 2002. SNI 03-6825-2002 tentang metode pengujian kekuatan tekan mortar semen portland untuk pekerjaan sipil. Jakarta.

BSN. 2004. SNI 15-7064-2004 tentang semen portland komposit. Jakarta.

Fitriawan, D. 2010. Studi pengelolaan limbah padat dan limbah cair PT XPasuruan sebagai upaya penerapan proses produksi bersih. Surabaya: Institut Teknologi Sepuluh Nopember.

Ismanto. 2010. Penelitian kinerja residu oli bekas, aspal minyak, dan minyak tanah (ROB-50) sebagai bahan peremaja pada daur ulang jalan aspal. Abstrak Skripsi Universitas Indonesia. Jakarta: Universitas Indonesia. http://lib.ui.ac.id/opac/themes/green/de tail.jsp?id=20238751\&lokasi=lokal.

Kemenkes. 2010. Permenkes No. 492 Tahun 2010 tentang persyaratan kualitas air minum. Jakarta.

Pemerintah Republik Indonesia. Peraturan Pemerintah No. 101 Tahun 2014 tentang pengelolaan limbah berbahaya dan beracun. Jakarta.

Spence, R.D., Shi, C. 2005. Stabilization and solidification of hazardous, radioactive and mixed wastes. Boca Rotton: CRC Press.
USEPA. 1986. Handbook stabilization/ solidification of hazardous waste. USA.

Voglar, G. E. \& Le`stan, D. 2011. Efficiency modeling of solidification/stabilization of multi-metal contaminated industrial soil using cement and additives. Journal of Hazardous Materials, 192: 753- 762 .

Wang, X., Fenga, C.W.N., Anderson, Y. Xing, L., Shang. 2012. Remediation of mercury contaminated sites - a review, J. Hazard. Mater. 221-222: 118.

Wijaya, A., Rahardjo, D.W.P.P. 2012. Pemanfaatan oli bekas sebagai bahan baku pembuatan bahan bakar cair (BBC) dengan metoda catalytic cracking dengan menggunakan katalis modernite. Semarang: Universitas Diponegoro.

Zain, A. M., Shaaban, G., \& Mahmud, H. 2014(1). Leachability of metal ions in TCLP leachate of solidified petroleum sludge. Key Engineering Material, 595: 1094-1098.

Zain, A. M., Shaaban, G., \& Mahmud, H. (2014(2)). Leachability of Solidified Petroleum Sludge. Advanced Material Research, 917: 123-133. 